\section{Staph: the NOse have it}

\section{By Lev Osherovich, Senior Writer}

A paper published in Science sheds light on why Staphylococcus aureus so successfully colonizes nasal passages and points to a new target, lactate dehydrogenase, for blocking this pathogen before it can cause systemic infection. ${ }^{1}$ But some companies are cautious about targeting $S$. aureus in the nose and about inhibiting bacterial lactate dehydrogenase, given the potential for interference with the human version of the enzyme.

One in three people harbors quiescent staph in the nasal cavities and passages. But in immunocompromised individuals the bacteria can thrive and spread systemically, causing septicemia and toxic shock syndrome. In addition, virulent, methicillin-resistant $S$. aureus (MRSA) strains, which shrug off many widely used antibiotics, have become pervasive and thus a growing public health threat. $^{2}$

The Science study, from a University of Washington team led by Ferric Fang, professor of laboratory medicine and microbiology, solves the mystery of why staph thrives in the nose, an environment full of immune cells and antimicrobial molecules that kill most other bacteria. The key to this is an inducible bacterial lactate dehydrogenase (LDH) enzyme that helps the bug resist nitric oxide radicals (NO•), antimicrobial molecules secreted by neutrophils and macrophages. ${ }^{3}$

The paper builds on previous work describing how staph adapts to high NO• environments such as the nose. ${ }^{4}$ In the new report, Fang's team monitored metabolite levels in staph cultures treated with $\mathrm{NO} \bullet$ in order to find the specific mechanisms that help staph survive.

"NO• is nature's antibiotic, a way for the body to arrest the growth of a number of pathogens," Fang told SciBX. The researchers found that $\mathrm{NO} \bullet$ interferes with pyruvate dehydrogenase and pyruvate formate lyase, two bacterial enzymes that are involved in processing pyruvate during glycolysis. "These enzymes are killed off by NO•, so the bug needs a way to adapt," said Fang.

With these enzymes incapacitated, bacteria develop a redox imbalance and stop growing. However, S. aureus eventually resumes growth, unlike a number of related but nonpathogenic microbes that cannot adapt to NO•. Fang's team discovered that this recovery results from the NO•-induced expression of an extra copy of the $L D H$ gene. $\mathrm{LDH}$ converts pyruvate to lactate.

According to Fang, the double dose of LDH relieves the redox imbalance caused by NO॰'s damage to the pyruvate-processing machinery. In
$\mathrm{NO} \bullet$-treated cells, electron transport gets backed up, leading to a shortage of $\mathrm{NAD}^{+}$, a coenzyme that shuttles away extra electrons generated in glycolysis. NO•-induced $\mathrm{LDH}$ relieves this shortage by opening up an alternative pathway that lowers pyruvate levels and restores $\mathrm{NAD}^{+}$ levels.

To test whether this effect was important for disease, Fang's team knocked out both copies of $L D H$ in a virulent staph strain. The knockout was sensitive to $\mathrm{NO} \bullet$ in a bacterial culture assay and avirulent in a mouse model of staph infection. However, the LDH-deficient strains could colonize and kill mice defective in NO• synthesis.

\section{Nasal intervention}

Most companies working on staph therapeutics are targeting bacteria in the blood stream or in wounds. According to Fang, however, targeting the pyruvate metabolism of staph to prevent nasal colonization could be a new strategy.

At least two biotechs-Xoma Ltd. and NovaBay Pharmaceuticals Inc.--are developing nonantibiotic bactericidal compounds to kill staph in the nose, although none of them is specifically directed at pyruvate metabolism.

Nasal eradication is Xoma's goal, according to Chief Biotechnology Officer Pat Scannon. "Clinical studies show that if you eradicate staph in the nasal epithelium, it conveys protection in hospitalized patients," Scannon told SciBX.

Xoma 629 is a topically administered antimicrobial that will start a Phase I trial for nasal staph infection this year. The compound is derived from a bactericidal, permeabilityincreasing protein.

Scannon expects pre-emptive nasal therapeutics such as Xoma 629 to be most useful in at-risk populations. "You wouldn't treat everyone in the whole world, but might use this in hospitals and dialysis settings," he said.

According to Fang, current treatment for nasal staph infection involves a course of mupirocin, a generic topical antibiotic. However, he said this strategy is increasingly futile because many patients do not stick to the multiweek regimen. Also, MRSA strains are resistant to mupirocin.

Like Xoma, NovaBay is also seeking to wipe out nasal staph. The company's AgaNase NVC-422 is a derivative of chlorotaurine, an oxidizing agent produced by innate immune cells, and kills bacteria through a mechanism similar to $\mathrm{NO} \bullet$.

CEO Ramin Najafi said NVC-422 broadly targets bacterial molecules rather than a single target like most antibiotics. This could make the therapeutic useful against a range of staph strains, including drugresistant ones. Najafi thinks that NVC-422 targets such common features of all staph bacteria that drug resistance will not be an issue. "If it can kill staph, it can also kill MRSA," he said.

AgaNase NVC-422 is partnered with Alcon Inc. and is in Phase II trials for nasal staph and Phase I trials for catheter-associated urinary tract infections. 


\section{TARGETS \& MECHANISMS}

Other companies were more cautious about going straight for the nose. Compounds that shut down staph's pyruvate metabolism are likely to be bacteriostatic rather than bactericidal, because low levels of $\mathrm{NAD}^{+}$ might slow down growth but not kill the bacteria. This leaves open a wider door for resistant mutants to arise. Also, nasal staph could be hard to eliminate because of the complex topography of nasal passages.

Elizabeth Posillico, CEO of Elusys Therapeutics Inc., said the Fang study was "very interesting" and that "the use of LDH to evade NO• is a very important pathway that could be used for new compounds that would reduce the virulence of staph." However, she thinks the bacterium would try to evade attempts to target $\mathrm{LDH}$ by developing resistance mutations.

Moreover, Posillico is unconvinced that nasal eradication is a practical goal. "I'm not sure you would want to treat everybody just on the presumption that they've got staph in their noses," she said. "You want to wait until an individual can't handle" the staph infection before medical intervention.

However, Posillico did suggest that inhibiting nasal staph growth in combination with systemic therapeutics such as the company's ETI-211 heteropolymer antibody could be "complementary" in fighting staph infections in at-risk patients with catheters or on dialysis.

Elusys is developing ETI-211 to treat staph. The preclinical compound consists of an antibody against staph coupled to an antibody against complement receptor 1 (CR1). When the antibodies bind their targets, bacteria are brought close to red blood cells, triggering the bactericidal complement cascade.

LDH also could be a difficult target because of its central role in human metabolism.

"I think it's too early to evaluate LDH as a therapeutic target," said
Joseph Patti, CSO of Inhibitex Inc. He said the reduction in virulence with LDH mutants was "compelling" but was concerned that compounds targeting LDH might adversely affect the human version of the enzyme, which is essential for glycolysis.

Inhibitex is developing Aurexis, an mAb against a surface protein common to most staph strains. Aurexis is in Phase II trials to treat complicated $S$. aureus bacteremia.

Fang agreed the challenge "is to design a drug that inhibits both forms of [staph] LDH without hitting the human form. We want to characterize the structure of these proteins to see if we can develop an inhibitor."

Fang is seeking industry collaborators to explore the possibility of developing $\mathrm{LDH}$ therapeutics for staph. "If it looks attractive as a drug target, it would be necessary to have access to a partner in industry," he said.

Fang has not sought patents for the work in the Science paper.

\section{REFERENCES}

1. Richardson, A.R. et al. Science; published online March 21, 2008; doi:10.1126/science.1155207

Contact: Ferric Fang, Department of Laboratory Medicine, University of Washington, Seattle, Wash.

e-mail: fcfang@u.washington.edu

2. Cegelski, L. et al. Nat. Rev. Microbiol. 6, 17-27 (2008)

3. Foster, T.J. Nat. Rev. Microbiol. 3, 948-958 (2005)

4. Richardson, A.R. et al. Mol. Microbiol. 61, 927-939 (2006)

COMPANIES AND INSTITUTIONS MENTIONED

Alcon Inc. (NYSE:ACL), Hunenberg, Switzerland

Elusys Therapeutics Inc., Pine Brook, N.J.

Inhibitex Inc. (NASDAQ:INHX), Alpharetta, Ga.

NovaBay Pharmaceuticals Inc. (AMEX:NBY), Emeryville, Calif.

University of Washington, Seattle, Wash.

Xoma Ltd. (NASDAQ:XOMA), Emeryville, Calif. 